\title{
MODELS OF STRUCTURES IN DIDACTICS
}

\author{
Stefan Niewitecki ${ }^{1}$
}

\begin{abstract}
The final aim of teaching students subjects, such as structural mechanics, reinforced concrete, and steel structures is to teach them how structures work in a given building as well as to provide them with skills enabling them to calculate and design structures. The behavioral model of the structure, contrary to the architectural model, which focuses mainly on the external form of the building, shows workings from both the static and dynamic points of view (e.g., the influence of the wind load, dead loads, and imposed loads) A series of fifteen behavioral models constructed of organic glass (poly-methyl methacrylate, also called Plexiglas ${ }^{\circledR}$ or metaplex) was built for didactic purposes for the academic staff of the Department of the Technical Fundamentals of Architectural Design at the University of Technology in Gdansk. This article presents the characteristics of these models, as well as their application in didactics. The usage of the models in specific educational subjects at the Department of the Technical Fundamentals of Architectural Design has been adopted as a classification criterion.
\end{abstract}

UDC Classification: 377, DOI: http://dx.doi.org/10.12955/cbup.v4.789

Keywords: didactics of architecture, structures, models of structure, architectural models.

\section{Introduction}

The methodology of any educational subject describes aims and methods of teaching that subject. One of the most important tasks of teaching methodology is to answer the question: "What are the best ways of teaching a specific subject?". The final aim of teaching students subjects, such as structural mechanics, reinforced concrete, and steel structures, is to teach them how structures work in a given building and to provide them with the skills that will enable them to calculate and design structures (Borusewicz, 1973). Thus, the conclusion is that the basic target of applying models of structures, in the didactics of architecture, is in making the static and structural issues in construction more understandable to students who, therefore, can see their impact on the final architectural form. The model of structure of a given building will differ from the architectural model because the former shows how a given structure works statically and dynamically (e.g., the influence of wind, dead, and imposed loads on structures), whereas the architectural model mainly shows the external form of the building. The assumptions regarding the models of structure in question should, therefore be as follows:

1. The models of structure should facilitate better understanding and memorizing of the issues constituting the subject of the classes and lectures;

2. The models of structure should better consolidate the acquired knowledge due to deeper understanding of the discussed issues;

3. The models of structures should, if possible, show a few options of the building structure; and

4. A set of the models of structure should be designed and designed in such a way so that it will constitute a coherent entity with regard to the discussed subjects; it would, therefore, be a kind of "bridge" connecting the classes of different subjects concerned with the structural issues. This would result in better acquisition of the knowledge on structural issues.

Models of Structures in Didactics: Description of the Models of Structure

A series of fifteen models constructed of organic glass (poly-methyl methacrylate, also called Plexiglas ${ }^{\circledR}$ or metaplex) was built for didactic purposes for the academic staff of the Technical Fundamentals of Architectural Design Department. The models were constructed so as to meet the assumptions given at point 1 , above. The aim of building the models was to test whether they constituted useful didactic tools.

The following describes the characteristics of the models and their application in didactics. The participation of the models in specific educational subjects at the Structural Engineering Department

\footnotetext{
${ }^{1}$ Stefan Niewitecki, Faculty of Architecture, Department of Technical Fundamentals of Architectural Design, Gdańsk University of Technology, Gdańsk, Poland, nievi@pg.gda.pl
} 
(now Technical Fundamentals of Architectural Design Institute) has been used as a classification criterion.

1. Subject: Structural mechanics - statically determinate structures

\subsection{Model No 1}

Description: the model of an overhanging simply supported beam

Issues to discuss:

1. The tensioned and compressed side of the beam both in the span and the support, basic notions of a bearing, a span, a bracket, a shear force, and a bending moment;

2. A notion of a fixed support, a hinged movable and immovable support, a notion of a theoretical span (a designed one). Technical solutions of hinged supports accepted in engineering, the concept of "wall to wall distance"; and

3. The correlation between the beam cross-section shape and its resistance to bending, beam deflections caused by forces working parallel or vertically to the longer side (height) of the beam cross-section, a concept of a moment of inertia (Kolendowicz, 1996).

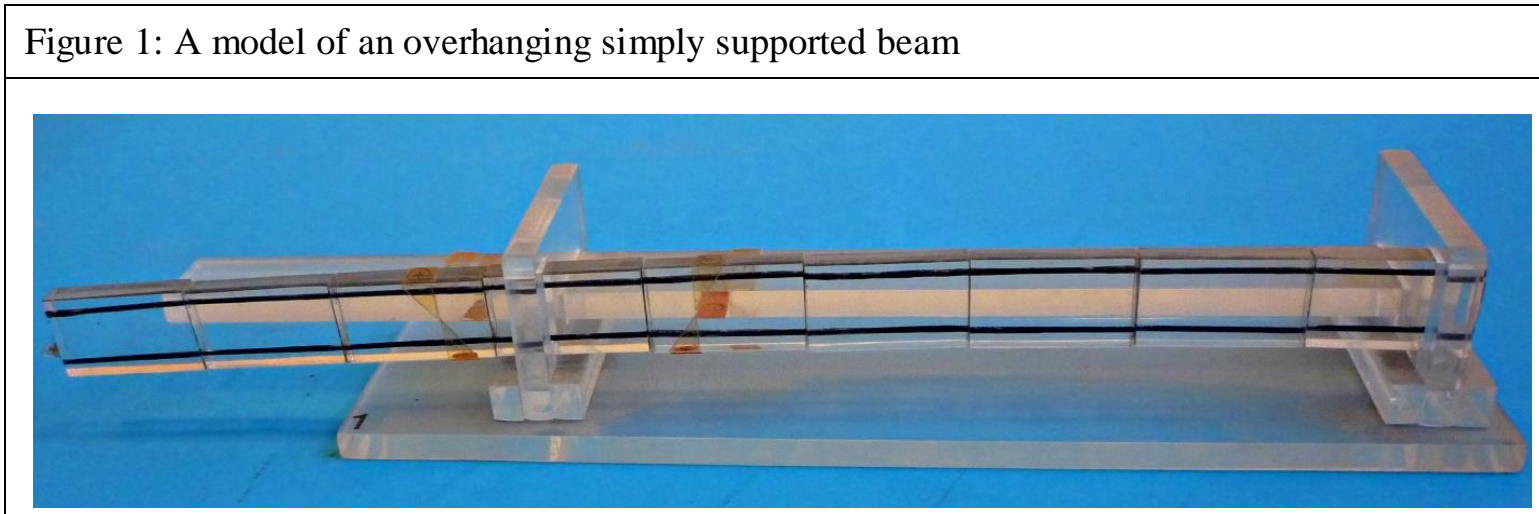

\section{Source: Author}

Figure 2: The presentation of the work of an overhanging simply supported beam

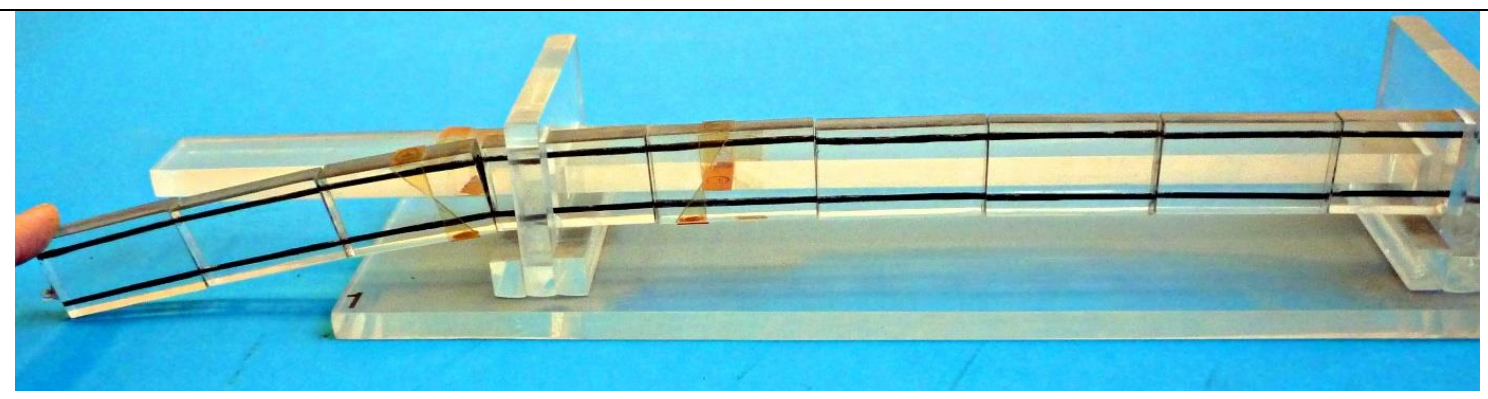

Source: Author

Figure 3: Figure 3: The presentation of the work of an overhanging simply supported beam span
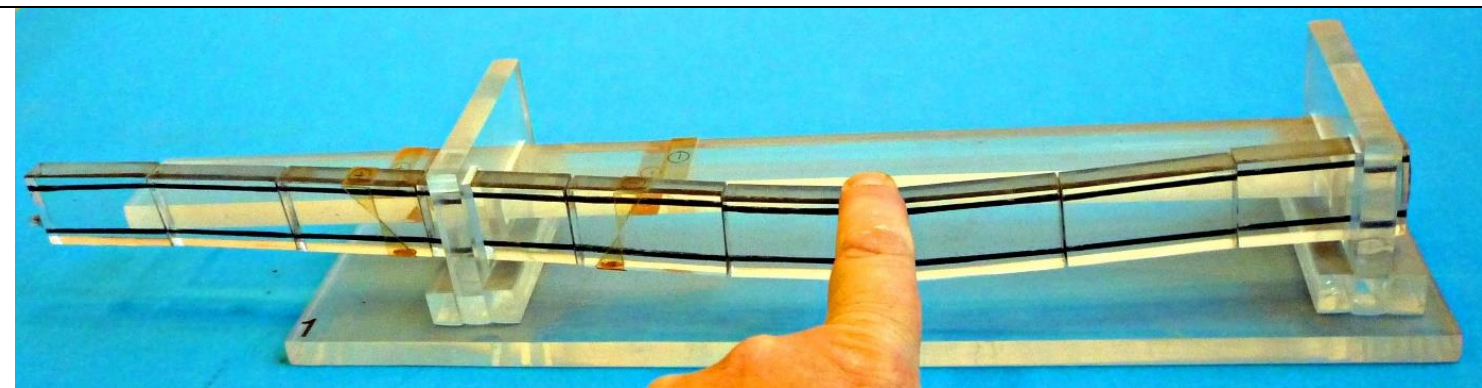

Source: Author 


\section{Subject: Structural mechanics - statically indeterminate structures}

\subsection{Model No 2}

Description: The model of a single-span and one-storey frame with four different static schemes Issues to discuss:

1. The way the loads are transmitted from the roof and walls onto the frame rafter and columns;

2. The spatial stiffness of the frame hall (crane beams, roof slabs, potentially also a vertical truss);

3. Static schemes of the frames:

- a statically determinate three-hinged frame,

- a frame statically indeterminate to one degree,

- a frame statically indeterminate to the second degree (not shown in the model), and

- a frame statically indeterminate to the third degree;

4. The profitability of using statically indeterminate systems (smaller bending moments than in statically determinate systems or a better distribution of these moments in a given statically indeterminate system); and

5. 5. The influence of the correlation between the moment of inertia of the columns and the rafter on the values of the bending moments in the columns and rafters in statically indeterminate frames.

\section{Subject: Reinforced Concrete Structures}

\subsection{Model No 3}

Description: a single-aisle, triple-span reinforced concrete hall structure

Issues to discuss:

1. The way loads are transmitted from the roof and the walls onto the rafters and columns (here, the rafters are joined by the slab without beams, however, the rafter loading used in model no 2 is more common);

2. One-way reinforced concrete slabs;

3. Reinforced concrete rafters and columns

4. The issue of articulated joints in reinforced concrete structures, difficulty in manufacturing them and, therefore, their unprofitability in monolithic structures; and

5. A reinforced concrete foundation base.

\subsection{Model No 4}

Description: Slab stairs

Issues to discuss:

1. Basic types of reinforced concrete stairs and their static components;

2. Advantages and disadvantages of slab stairs in comparison to slab with beam stairs and stringer stairs; and

3. The reinforcement of the slab - the difficulty in reinforcing the place where the landing and the stairway are joined and the resulting difficulty in the reinforcement of the simply supported reinforced concrete beams.

\subsection{Model No 5}

Description: Slab with beam stairs

Issues to discuss:

1. Work and reinforcement of the slabs of the landing and the stair flight in the slab with beam monolithic stairs ( $M=1 / 10 \mathrm{ql} 2,1=$ the span of the flight of stairs $)$ and precast ones $(\mathrm{M}=1 / 8$ q12); and

2. Work and reinforcement of reinforced concrete beams shown with the help of the support beam of the landing and the stair flight slabs.

\section{Subject: Precast Structures}

\subsection{Model No 6}

Description: The model of structure of the pre- or post-tensioned beam

Issues to discuss: 
1. The essence of pre-stressing of structural components; and

2. The beams pre-stressed in the factory or in situ in terms of the comparison of pre-tensioned and post-tensioned beams, the advantages and disadvantages of both types.

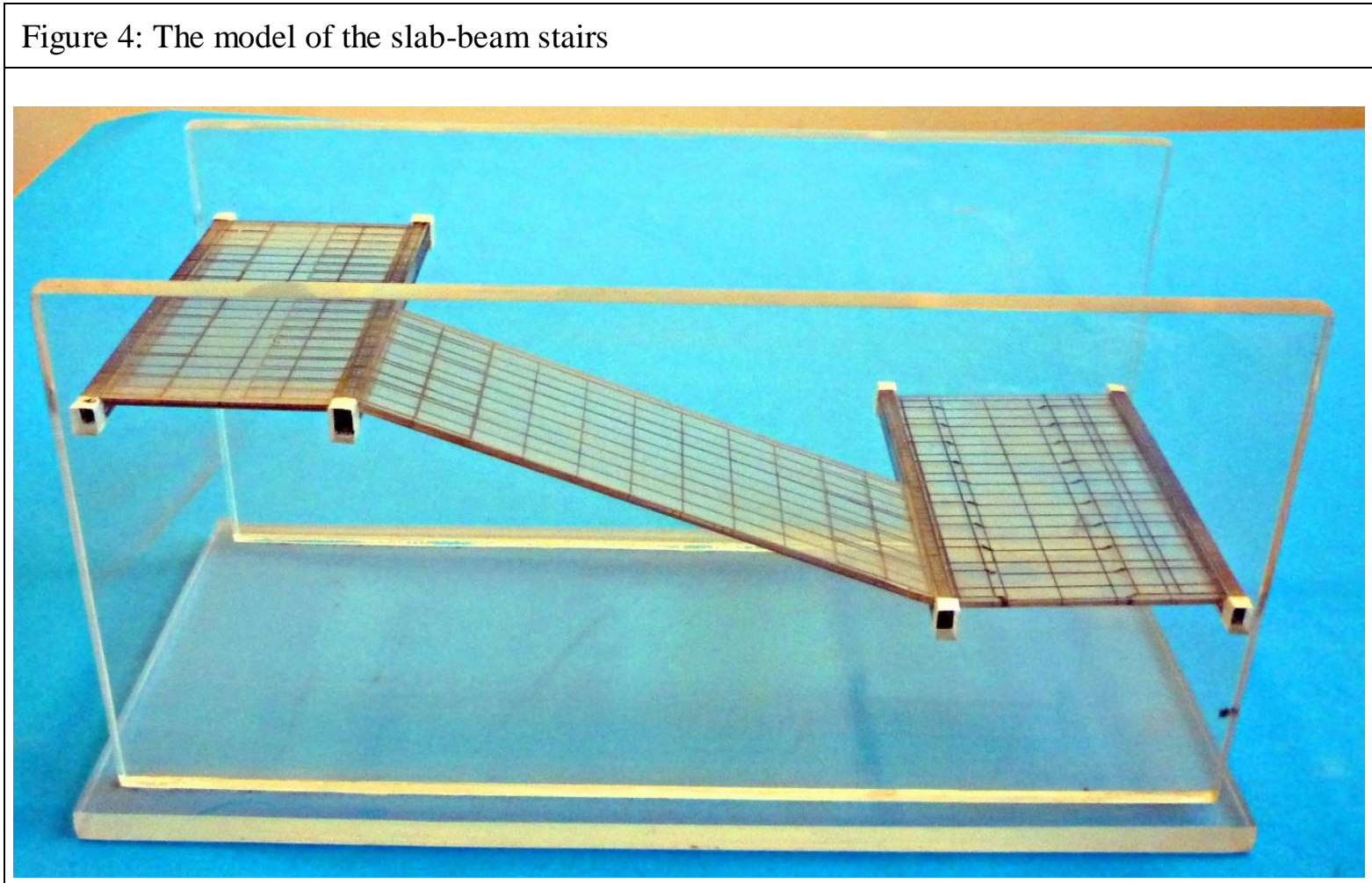

Source: Author

Figure 5: The model of the slab-beam stairs. A bottom reinforcement of the stair flight slab and the support beam

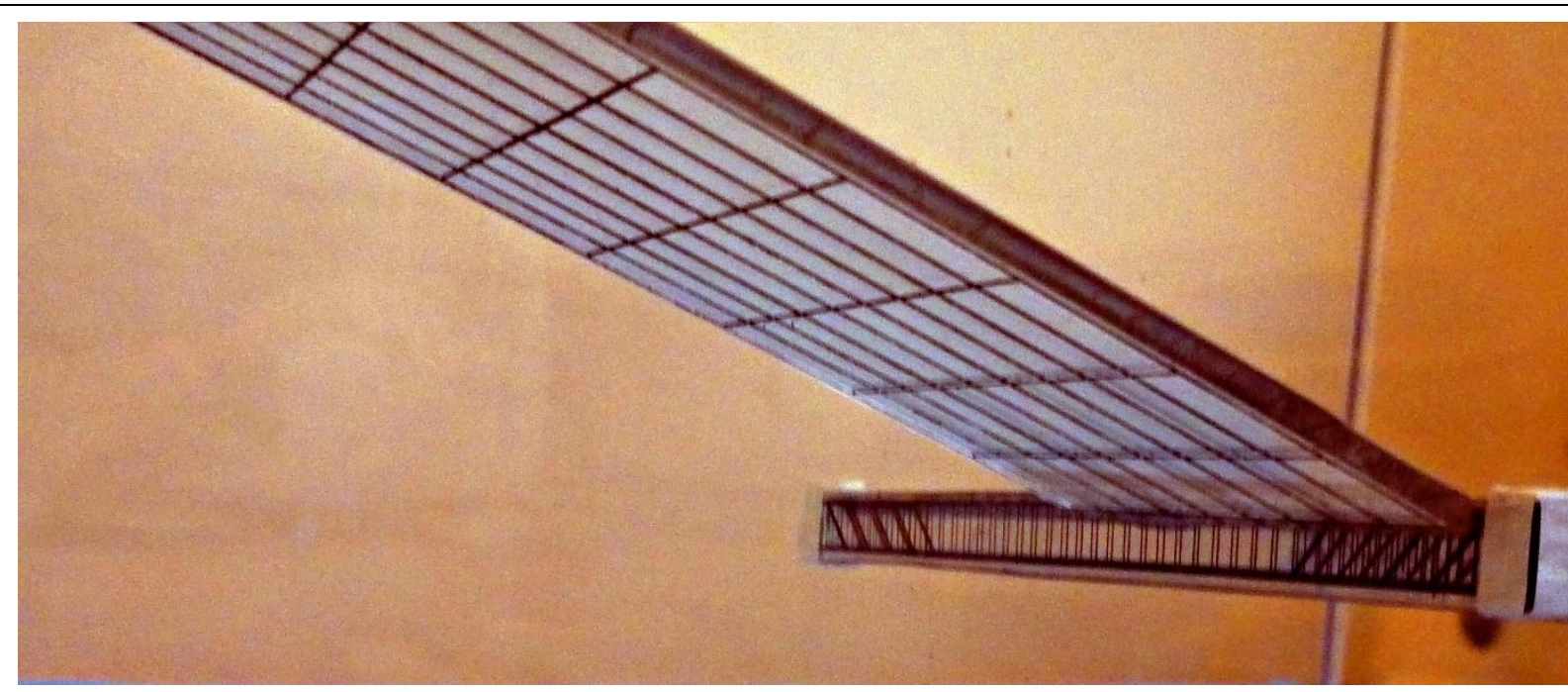

Source: Author

\section{Subject: Steel Structures}

\subsection{Model No 7}

Description: the model of the industrial hall with a crane along with different options of column structures and a steel roof (plane trusses); a single-storey, single-aisle hall 
Issues to discuss:

1. Foundation bases, i.e., kinds and reinforcement;

2. Variants of curtain walls; ground beams, intermediate support, free-standing beams, columns, and the ways the wind loads are transmitted (pressure and sucking) from the walls onto the columns;

3. Variants of columns in the halls of a big span; monolithic or precast reinforced concrete columns (solid or with openings or one- or two- branch types); Steel columns as plate girders, trusses, or double T-section box types;

4. Variants of crane beams, crane load bearing structures, and review of the subject of "influence lines" (structural engineering); reinforced concrete pre- and post-tensioned crane beams with a square, and T- and double T-cross section; plated crane steel beams (double T-section or box ones), truss crane steel beams, pre-stressed steel beams, or with tendons;

5. The way the load is transmitted onto the roof trusses according to the truss span and the roofing type, supporting the roof plates directly on trusses, or with the help of purlins; purlin types as in rolled double $\mathrm{T}$ sections or trussed purlins;

6. The role of bracing in structure stability, side wall bracing (a cross brace or a portal frame), roof truss vertical bracing, or roof slope bracing; and

7. Summary of cross section dimensions of the columns in buildings having larger dimensions, and roofing of these buildings, which introduces the most common difficulty for students in their bachelor or master theses.

\section{Subject: Special structures (of a large span)}

\subsection{Model No 8.}

Description: a cloister vault and a cross vault

Issues to discuss:

1. The development of thin-walled vaults from the historical point of view (barrel vault, cloister vault, cross vault, sexpartite rib vault, a dome resting upon a drum, squinches, or pendentives; and

2. Vaults as prototypes of contemporary thin-walled structures compensating compression.

\subsection{Model No 9}

Description: The model of a single-storey, single-aisle reinforced concrete hall covered with three cylindrical shells

Issues to discuss:

1. Static work and concrete reinforcement of the cylindrical shell, end joists, and roof diaphragms; and

Work and reinforcement of the columns of longitudinal walls and gable walls.

Figure 6: The model of an industrial hall with a crane. The options of columns of different structures are shown

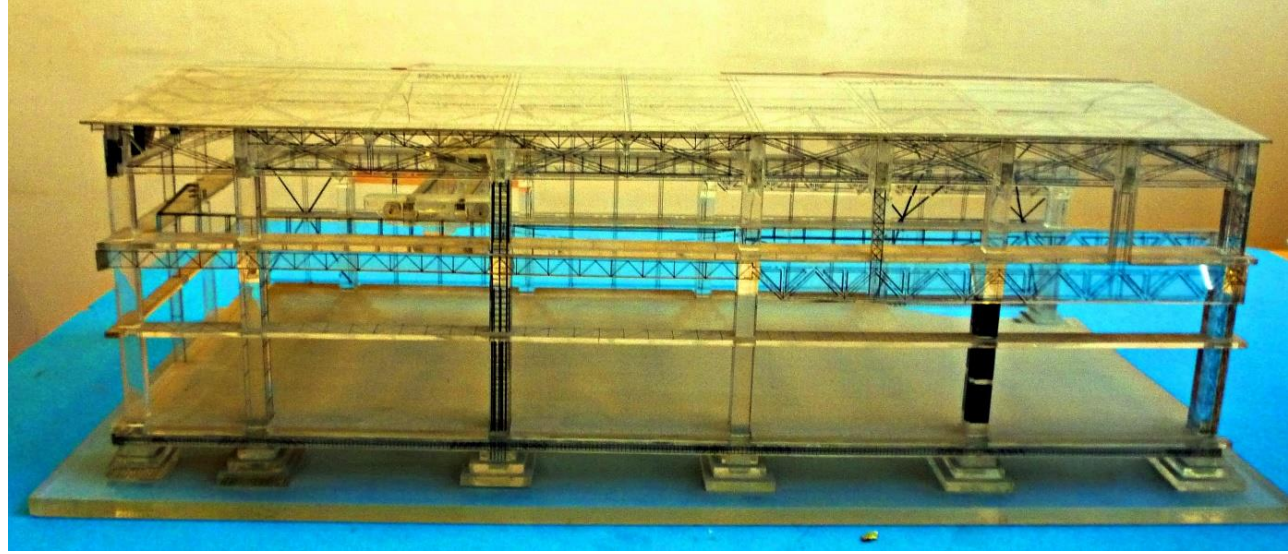

Source: Author 
Figure 7: The model of an industrial hall with a crane showing the gable wall view

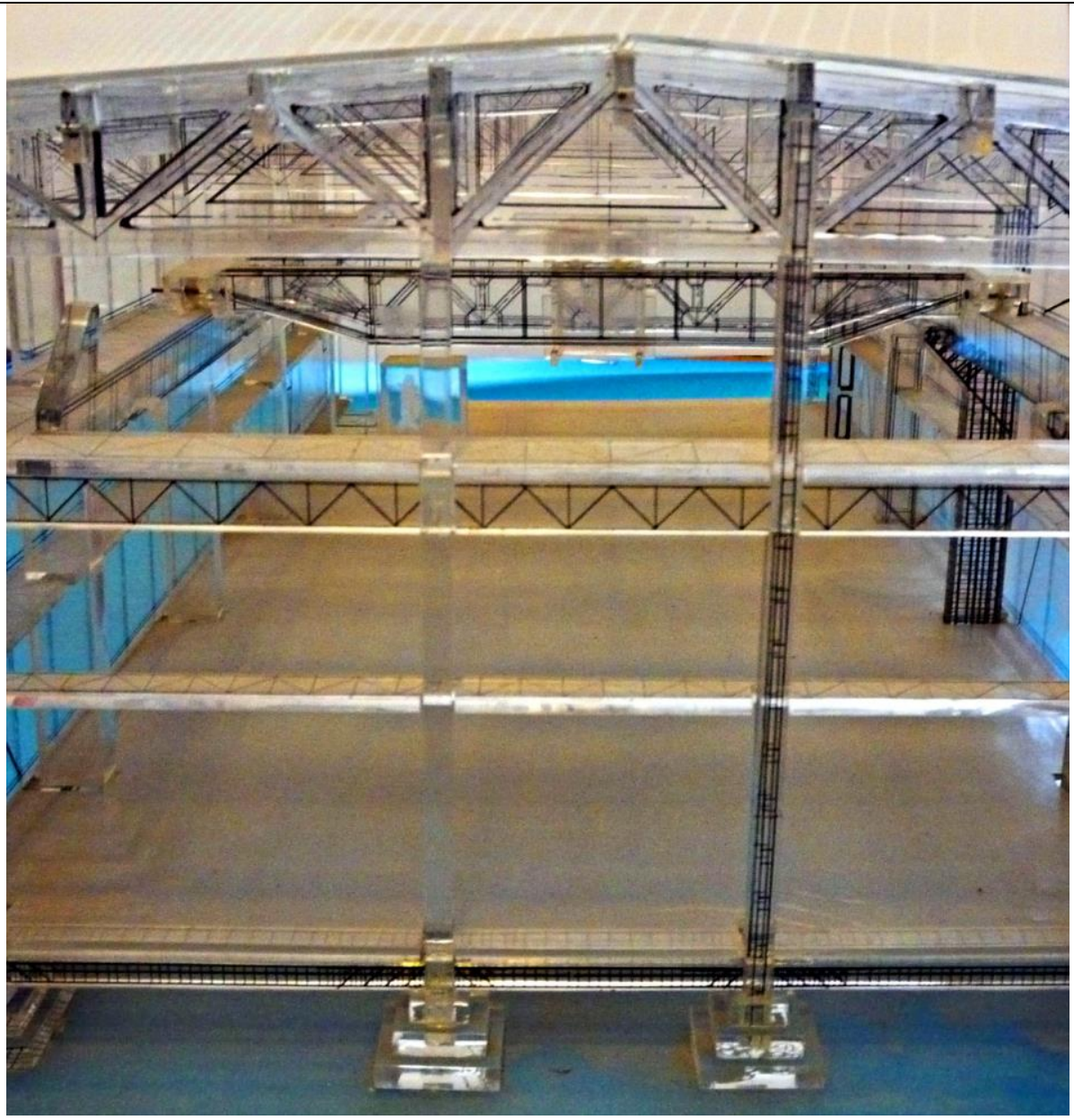

Source: Author

Figure 8: The model of a single-storey, single-aisle reinforced concrete hall covered with three cylindrical shells

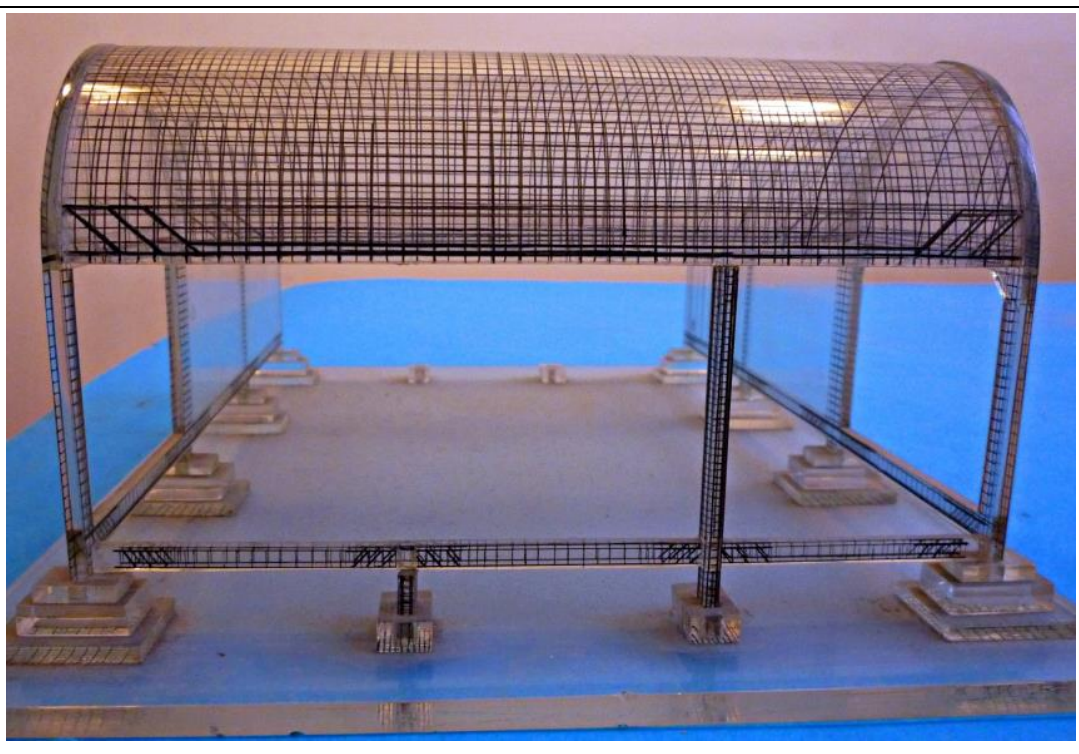

Source: Author 


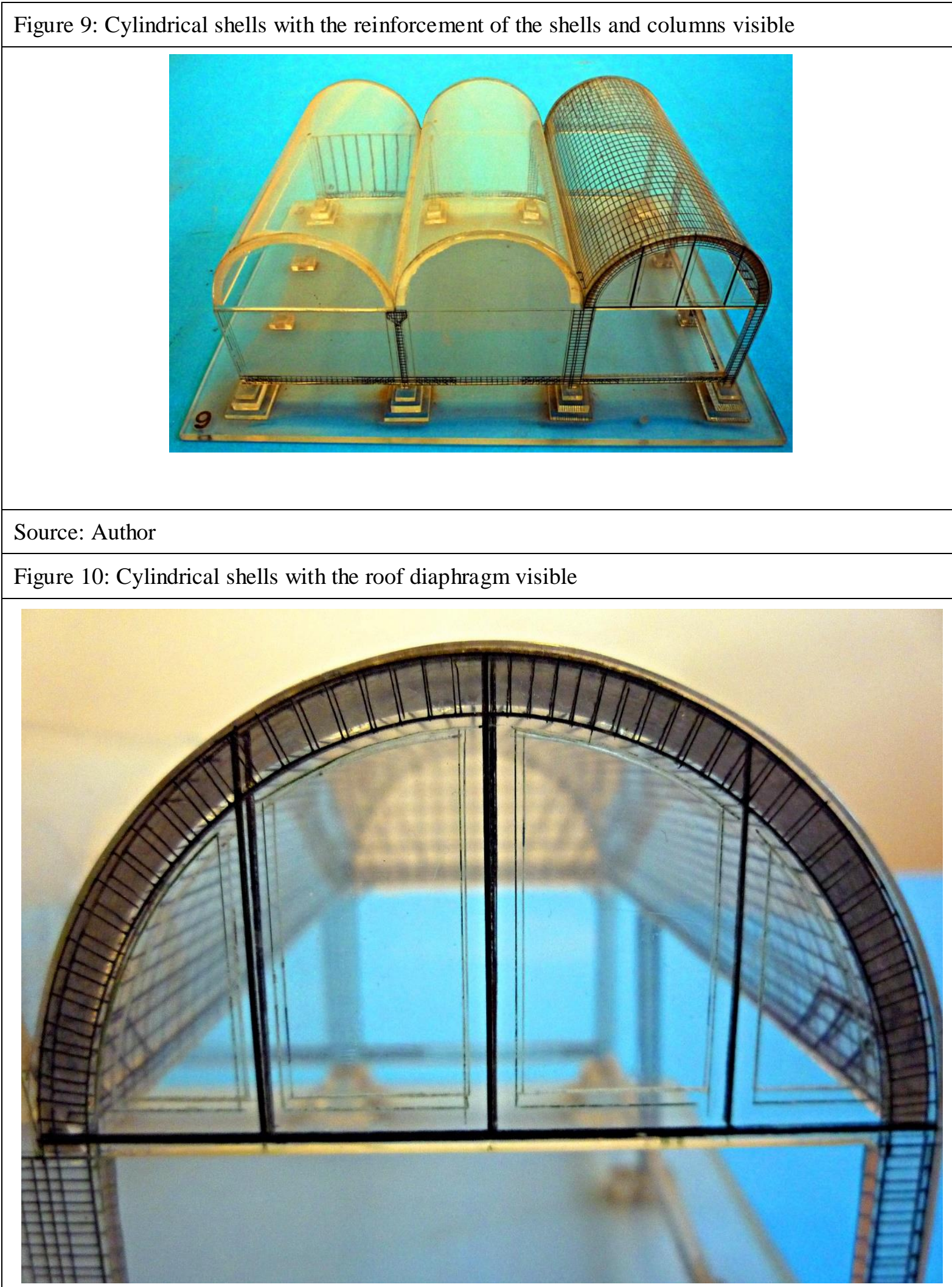

Source: Author

\section{Conclusion}

The models of structures presented in this article support the rationale for using such didactic tools. Notably, the models of structures fulfilled their purpose in the didactics of architecture. The models provided students with better understanding and memorizing of the subjects of 
lectures and classes, and has led to better consolidation of acquired knowledge. The use of models during both the classes of structural mechanics and that of reinforced concrete and special structures have enabled students to comprehend a deeper level of the scope of knowledge with regard to structures.

The positive results of the application of the abovementioned models of structure in didactics comprise, among other advances, further development of technology by students, who, as part of the classes of "Principles of Building Engineering" designed the structural models of roof trusses and wooden walls (Figure $11 \& 12$ ).

Taking into consideration the development of computer science, the substitution of "physical" models by ones that are generated on the computer appears well justified. An unquestionable advantage of computer generated models is the possibility of showing the animation of the component deflection resulting from the loads.

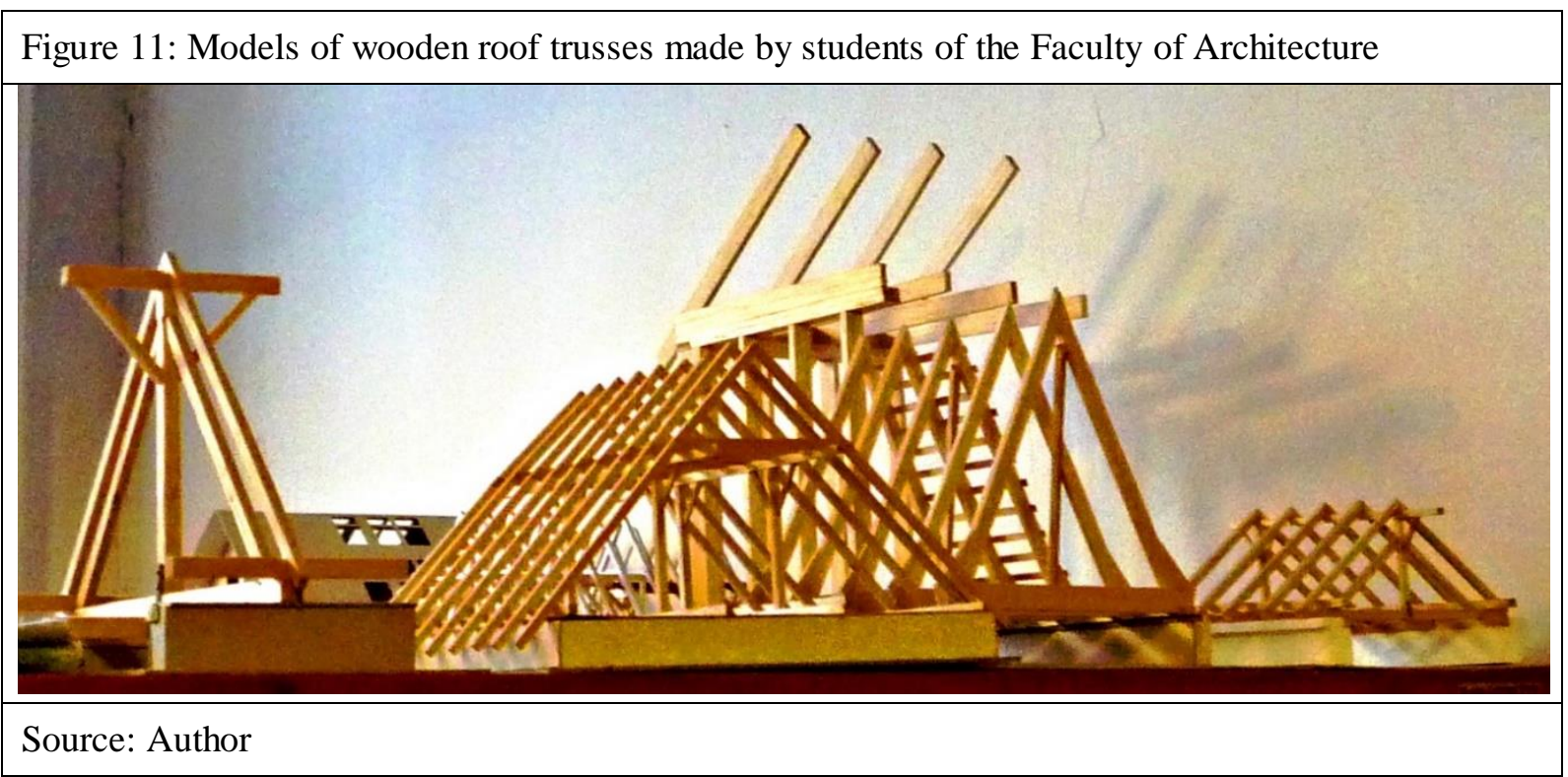

Figure 12: Models of wooden roof trusses made by students of the Faculty of Architecture.

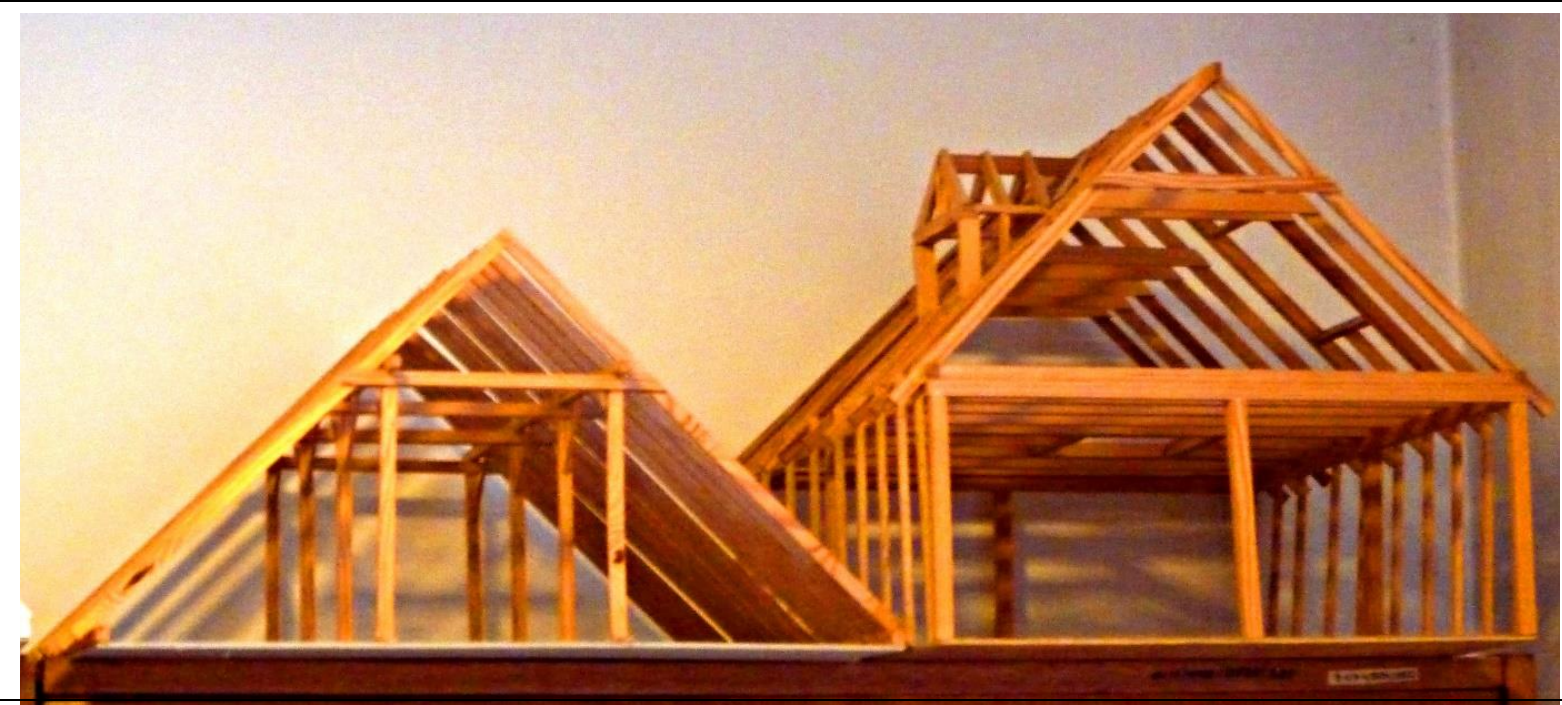

Source: Author

\section{References}

Borusewicz, W. (1973). Konstrukcje Budowlane dla Architektów [Building Structures for Architects], Arkady.

Kolendowicz, T. (1996). Mechanika Budowli dla Architektów [Structural Mechanics for Architects], Arkady. 